\title{
Artificial Intelligence Empowered Educational Reform: Current Trends and Considerations
}

\author{
Jianhui Yang ${ }^{1 \text { st,1,a }}$, Lingyin Peng ${ }^{1 \text { st,2,b }}$, Jianxin Li ${ }^{2 n d, 3, c}$ \\ ${ }^{1}$ Guangdong University of Foreign Studies South China Business College \\ ${ }^{2}$ Guangzhou University \\ ${ }^{3}$ Jiangmen Polytechnic \\ 1614396261@qq.com \\ b2001110013@e.gzhu.edu.cn,1178138309@qq.com \\ c1341981644@qq.com
}

\begin{abstract}
With the trend of technological reforms, artificial intelligence as a new generation of information technology empowers educational reforms to be an important part of current educational reforms. Starting from the trend of artificial intelligence technology and education reform, integration, and innovation, this article thinks about the balanced development of future education in the wave of the intelligent age, in order to promote the reshaping of the education ecology, so as to complete the purpose of cultivating future talents.
\end{abstract}

Keywords: Artificial Intelligence, Educational reform, Future education, Reshaping the Educational Ecosystem.

\section{PREFACE}

A hundred years ago, China's first educational system was promulgated, and the development of modern education in China has been more than one hundred years. The college entrance examination system was restored in 1977, and the development of contemporary education in China has been 44 years old. After more than 40 years of development and reform, my country's education has achieved far-reaching development. Education is providing a steady stream of power and resources for China's modernization. Meanwhile, China continued education reform.

\section{TO EDUCATION INTELLIGENT ERA}

In 2019, under the organization of the United Nations, more than a dozen international organizations and more than 100 countries jointly discussed the strategic goals and effective experience of using artificial intelligence to promote education reform. The release of the 'Beijing Consensus-Artificial Intelligence and Education' provides guidance and suggestions for the use of artificial intelligence technology to achieve the sustainable development of education in 2030.

Entering the $21 \mathrm{st}$ century, China's artificial intelligence has entered an active period under the advancement of a new generation of information technology. With the support of big data and virtual reality, artificial intelligence is transforming to datadriven, human-machine collaboration, cross-border integration, and group intelligence [1]. According to the current development, it is also obvious that artificial intelligence accelerates the transformation process of various industries. In the mutual penetration of various fields, it is also obvious that due to its precision and efficiency, it will bring a new round of dividends to the development of various industries. Nowadays, artificial intelligence has been applied in various industries, such as healthcare, financial economy, education, industrial manufacturing, urban management, etc. Take education as an example. With the intelligentization of the teaching environment, teaching concepts, teaching aids, and teaching management, education has entered the age of intelligence.

\section{PRACTICE AND APPLICATION OF ARTIFICIAL INTELLIGENCE AND EDUCATION}

In 2019, General Secretary Xi Jinping pointed out at the International Conference on Artificial Intelligence and Education that the important mission of education in 
the era of artificial intelligence is to cultivate a large number of high-end talents with innovative capabilities and a spirit of cooperation [2].

The current international competition is a contest of comprehensive national strength. In order to meet the major challenges of talent training in the new era, and achieve the strategic goal of a talented nation, the key is education.

$$
\begin{aligned}
& \text { 15.72\% } 6.73 \% \\
& \text { - Computer vision } \\
& \text { - Smart driving } \\
& \text { - Smart robot } \\
& \text { - Deep learning technology } \\
& \text { - Speech Recognition }
\end{aligned}
$$

Figure 1.The structure chart of the application volume of the first-level technology branch of artificial intelligence in China

In recent years, the education sector has gradually increased its support for artificial intelligence. According to data, in 2018, the education department identified 612 'new engineering' construction projects, of which artificial intelligence accounted for $9.8 \%$. Several science centers and innovation centers have been built in Zhejiang University, Harbin Institute of Technology, Fudan University, etc. As of 2020, a total of 31 artificial intelligence colleges and 24 artificial intelligence research institutes have been established [3].

Driven by artificial intelligence, virtual tutors, educational robots, scene-based education, automatic correction of homework, online question-answering with photos, and language recognition and evaluation have been marketed. Artificial intelligence is considered to be an important factor that cannot be ignored in future education [4]. Therefore, thinking about the integration trend of education and intelligence is the basic starting point for our research on future education.

\section{THE FUTURE TREND OF ARTIFICIAL INTELLIGENCE AND EDUCATION}

In order to achieve the above goals, China has issued a series of documents to promote the application of artificial intelligence in education in recent years. In 2018, the 'Education Informatization 2.0 Action Plan' and the 'Higher Educational Intelligence Innovation Action Plan' were released to put forward new goals for intelligent education, and further promote the talent training plans of universities in the field of artificial intelligence. In 2019, 'China Education Modernization 2035' clarified the goal of 'becoming a powerful country in education', put forward the time requirement of 'achieve education modernization in general in 2035', and included the promotion of education reform in the era of intelligence among the ten strategic tasks of education modernization. This shows that China attaches great importance to it.

\subsection{Innovative teaching resource supply}

In the foreseeable future, the integration of artificial intelligence and education will help increase the capacity of education. The new educational information ecosystem is based on 'broadband network school-toschool, high-quality resource class-to-class communication, online learning space for everyone', through the 'education resource public service platform and education management public service platform' to optimize educational resources. Teaching resources will develop toward the characteristics of 'openness, systematization, and diversification' [5].

\begin{tabular}{rrrrrrrrrr}
\hline Time & 2011 & 2012 & 2013 & 2014 & 2015 & 2016 & 2017 & 2018 & 2019 \\
patents & 14015 & 18514 & 23322 & 27874 & 38506 & 58302 & 80380 & 94539 & 10051 \\
\hline
\end{tabular}

Figure 2.Artificial intelligence patent applications in each year

\subsection{Innovate learning methods and promote personalized learning}

Most public schools in China adopt large-class teaching methods. It is a big challenge for teachers to tap the potential of students. Artificial intelligence technology will more effectively assist teachers to understand students and develop personalized learning for learners on this basis. Plan to achieve student- centered [6]. The more you use it, the more accurately you can analyze individual learning situations and provide targeted learning materials.

\subsection{Cultivate new skills and promote lifelong learning}

In 2019, Vice Minister of Education Denghua Zhong mentioned in the Smart Education Strategy Research 
Seminar: integrating smart education into the modernization of education [7]. In the future, under the challenge of technological informationization, the labor force needs to have strong practical and innovative capabilities to improve its competitiveness in the labor market. The intelligent learning platform promotes learners to break through the constraints of space and time and obtain learning resources. According to Korn Ferry's survey, more than a quarter $(27 \%)$ of human resource professionals say that the re-training of employee skills is the primary task of the organization [8]. In the future, not only students, but also those who are already on the job, the continuous improvement of soft power and hard skills will gradually become normal.

\subsection{Reduce the burden on teachers and empower teaching}

It is also good for teachers. It will help teachers to reduce burden and increase efficiency in their work [9]. Artificial intelligence will further exert the maximum effect of 'teaching assistants', assisting teachers to deal with the tedious and repetitive parts of daily teaching tasks, so that it puts more energy into teaching to improve teachers' personal professional quality. With the aid of big data analysis, teachers' teaching guidance and quality evaluation of students will also be more professional and comprehensive [10].

\subsection{Digital education, reshaping the education ecology}

After many years of education reform, the current education development is transforming to digital education. The combination of 'artificial intelligence + education' makes all aspects of learning more open and flexible, thereby avoiding the 'Matthew effect' of excellent teaching resources [11]. The new generation of information technology led by artificial intelligence has triggered a chain breakthrough in teaching concepts, teaching environment, and teaching management, laying the foundation for reshaping a new education ecology.

\section{THOUGHTS ON THE DEVELOPMENT OF 'ARTIFICIAL INTELLIGENCE + EDUCATION'}

With the assistance of artificial intelligence, education will further cultivate high-end talents with digital literacy for the society. Highly literate people with the above characteristics will also promote the rapid development of artificial intelligence, so that artificial intelligence and education can achieve sustainable integration and two-way empowerment. However, this ideal form cannot be fully demonstrated in a short time, requiring a lot of investment and long-term optimization.

At present, artificial intelligence is in the stage of 'weak intelligence' [12], and the problems faced by education in our country are equally severe-uneven educational resources, unbalanced teachers, a small proportion of education investment, and conservative teaching methods. The new model of 'artificial education + education' not only lowers the threshold for obtaining high-quality resources, but also favors disadvantaged groups in society [13]. It is the goal of education reform to achieve better and balanced development of educational resources.

China has decided to carry out a special rectification of off-campus training institutions to provide new development ideas for 'artificial intelligence + education' at the initial stage. Its precision and comprehensive advantages will help parents better understand their children's learning ability and talents. Avoid blindly and proliferately registering interest classes, so as to better implement the 'burden reduction policy.'

\section{CONCLUSION}

While developing, education will also face a series of ethical issues such as replacing the human brain with machines. The positioning of teachers, students and even parents in the 'artificial intelligence + education' informatization reform will affect 'artificial intelligence and education.' However, it is foreseeable that with the help of artificial intelligence, future education will develop towards individualization, intelligence, and informatization, and the teaching revolution will also enter a new journey.

\section{REFERENCES}

[1] Xinhua News Agency. Xi Jinping presided over the ninth collective study of the Political Bureau of the CPC Central Committee and delivered a speech [EB/OL]. http://www.gov.cn/xinwen/201810/31/content_5336251.htm. 2018-10-31.

[2] Xinhuanet. Xi Jinping sends a congratulatory letter to the International Conference on Artificial Intelligence and Education [EB/OL].http://www.xinhuanet.com/politics/leader s/2019-05/16/c_1124502111.htm,2019-05-1.

[3] Ministry of Education. Deeply promote the construction of "new engineering department" [EB/OL].

http://www.moe.gov.cn/jyb_xwfb/xw_fbh/moe_26 06/2019/tqh20191031/sfcl/201910/t20-191031_406 260.html.2019-10-31.

[4] Guan Chenghua, Chen Chaofan, An Xin. The Trend of Educational Innovation in the Intelligent Era and the Enlightenment of Future Education [J]. China Audio-visual Education,2021(07):13-21.

[5] Liu Dejian, Du Jing. The development trend of 
integrating artificial intelligence into school education $\quad[\mathrm{J}]$. Open Education Research,2018,24(4):33-42.

[6] Han Min. Speed up the construction of a lifelong learning system that serves the whole people [J]. Lifelong Education Research,2020,(3):4-6.

[7] CCTV. Zhong Denghua, Vice Minister of Education: Integrate smart education into the modernization of education

[EB/OL]. https://baijiahao.baidu.com/s?id=16286836119617 $24741 \& w f r=$ spider\&for=pc.2019-03-22.

[8] World Wide Web. Korn Ferry Unlocks New Global Talent Trends in 2020 [EB/OL]. https://baijiahao.baidu.com/s?id=16550388319732 $28763 \&$ wfr $=$ spider \&for $=$ pc.2020-01-07

[9] Huang Ronghuai. Artificial intelligence transforms education has become a global consensus [J]. China Education Network,2019,(6):28-29.

[10] Xia Wenbin, Zhang Ruochen. Artificial Intelligence and the Education Revolution [J]. Journal of Shihezi University (Philosophy and Social Sciences Edition),2021,35(03):125.

[11] Xu Ruiyue, Liang Haonan, Zhou Qin. Artificial intelligence empowers education reform : International experience and future prospects $[\mathrm{J}]$. Digital education,2021,7(03):21-26.

[12] Intelligence and integration [J]. China Information Technology, 2013(20):34-35.

[13] China Education News. Education is the country's top priority, Party plan [EB/OL]. https://baijiahao.baidu.com/s?id=16457024882252 $34368 \& w f r=$ spider\&for=pc.2019-09-26. 